INTROducción y RePERTORIO Bibliográfico Para El Estudio Traductológico Y Contrastivo de La Fraseología Española

TAREK SHABan MoHammad Salem

Universidad de al-Azhar 


\title{
InTRoducción y RePertorio Bibliográfico PARA El ESTUdio \\ Traductológico Y Contrastivo de La Fraseología EsPañola
}

\section{INTRODUCTION AND BIBLIOGRAPHIC REPERTOIRE FOR THE TRANSLATION AND Contrastive Study OF SPANish Phraseology}

\author{
TAREK SHABAN MOHAMMAD SALEM \\ Universidad de al-Azhar \\ tarek_spanish@yahoo.com
}

\section{RESUMEN}

Durante las cuatro últimas décadas, se ha registrado un auge en el campo de investigación de la fraseología española, una disciplina que ha podido consolidarse en el ámbito de los estudios hispánicos. A lo largo de dicho periodo, han aparecido diversos estudios de índole diferente, y se destacan aquellos que tratan la fraseología desde el aspecto traductológico y contrastivo. Este trabajo tiene como fin llevar a cabo un repertorio bibliográfico de los relevantes trabajos publicados en estos dos campos para orientarles a los investigadores e interesados de lo que se ha realizado hasta el momento al respecto. Dicho repertorio incluye artículos de revistas, libros, tesis doctorales, ponencias de conferencias celebradas sobre la disciplina fraseológica, etc., que sirven como guía para los futuros investigadores que quieran seguir investigando en este terreno.

Palabras Clave: Fraseología - Traducción - Fraseología Contrastiva - Repertorio Bibliográfico

\section{AbSTRACT}

During the last four decades, there has been a boom in research in Spanish phraseology; one of the major disciplines of Hispanic studies. During this period, there have been several studies which discuss different phraseology-related aspects, such as translation of phraseology and contrastive phraseology. This work aims to develop a bibliographical repertoire of the relevant works in order to inform all researches that have been done on these two aspects so far. This repertoire includes academic articles, books, doctoral theses, conference proceedings, etc. on phraseology. The present article serves as a guide for future researchers who want to continue studying in this field.

KEY WORDS: Phraseology - Translation - Contrastive Phraseology - Bibliographic Repertoire 


\section{تقيم لدراسة التعبيرات الاصطلاحية وقائمة مراجع بِبليوغرافية من المنظورين الترجمي والتقابلي}

خلال العقود الأربعة الماضية، كان هناك ازدهارٌ في مجال البحث في حقل اللغويات الإسبانية،

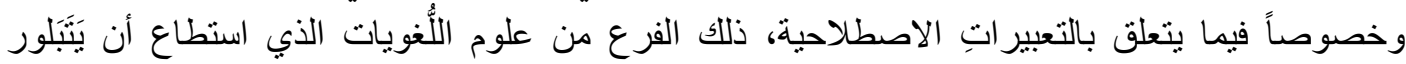

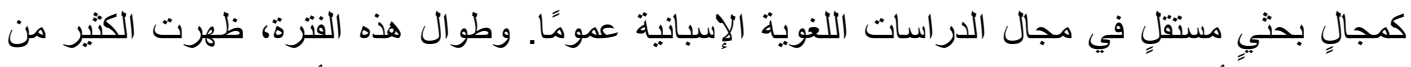

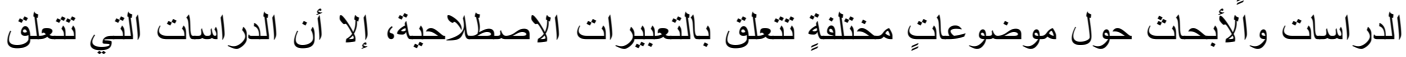

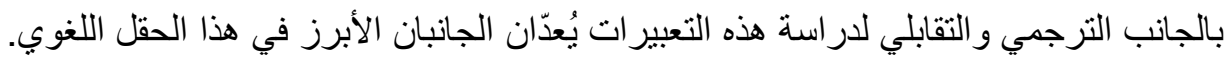

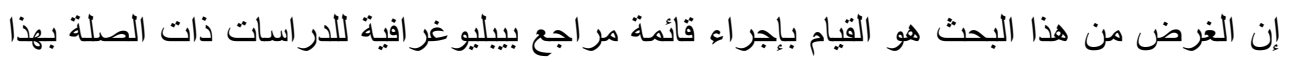

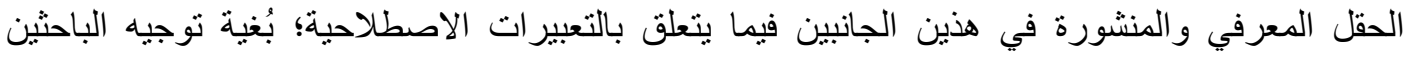

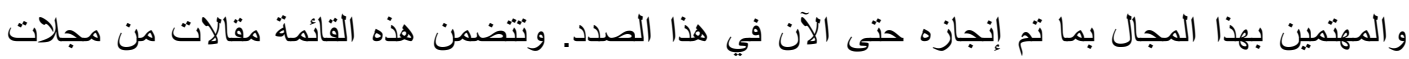

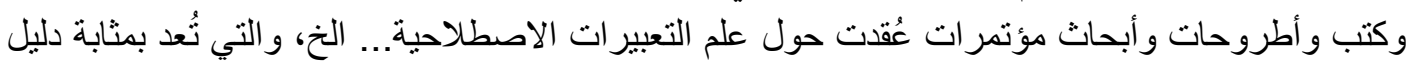

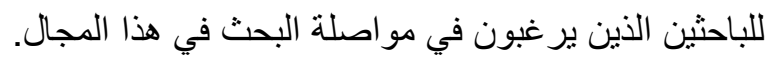

ومن خلال هذا النوع من الدراسة، يمكن التعرف على عدة نقاط رئيسية في مجال التعبيرات

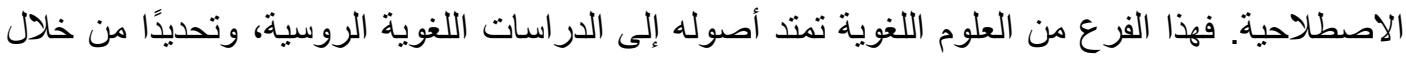

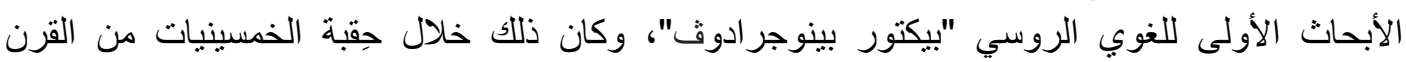

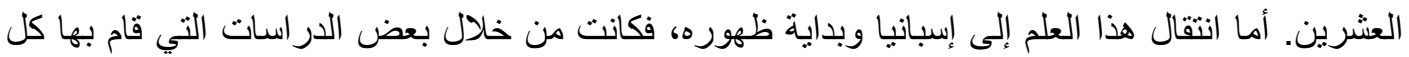

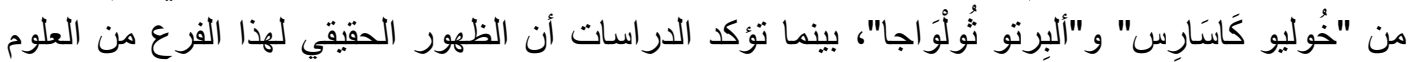

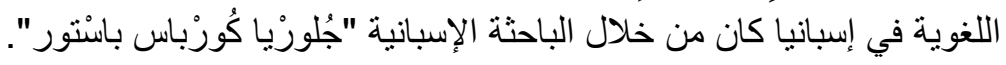

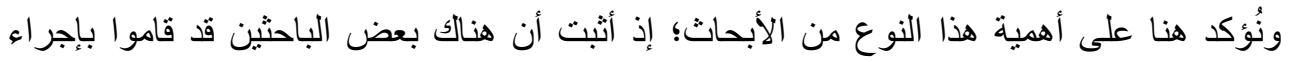

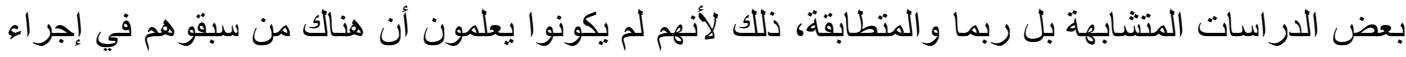

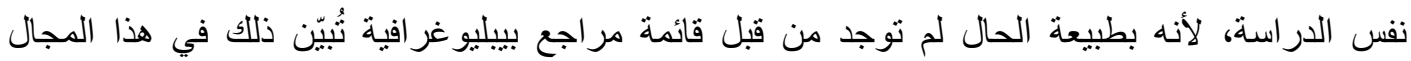

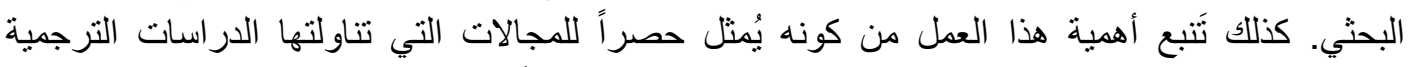

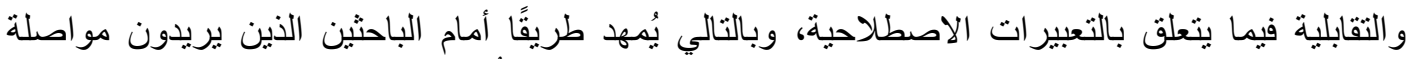

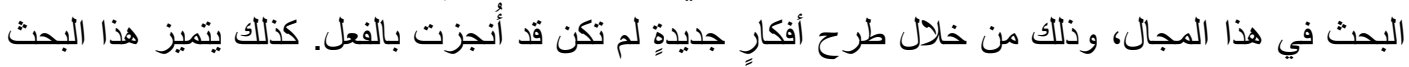

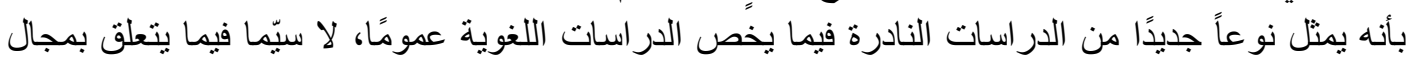
علم التعبيرات الاصطلاحية.

كلمات مفتاحية: تعبيرت الاصطلاحية - ترجمة - تعبير ات اصطلاحية تقابلية - مر اجع بِبلو غر افية 


\section{Introducción}

Durante los últimos años, el campo de la fraseología ha incitado a muchos investigadores, tanto en el mundo árabe como en Occidente para llevar a cabo algunos trabajos relacionados con dicha disciplina. La fraseología, de hecho, se considera como un campo de estudio complejo, sobre el que muchos de los estudiosos han tratado distintas fracciones relacionadas con esta disciplina lexicográfica con el fin de establecer las pautas que han podido desempeñar un papal trascendente en su desarrollo.

Es de confirmar que la fraseología es una disciplina lingüística que nació a principios del siglo XX, fundamentalmente por dos escuelas, la francesa y la rusa. El retraso de su nacimiento en España es evidente, ya que apareció a reflejarse en los estudios hispánicos hasta mediados de siglo XX. Desde su aparición en España, se inició una serie de trabajos de distintas perspectivas coherentes a dicha rama lingüística, sobre todo trabajos relacionados con el aspecto traductológico y contrastivo.

Todos los que estudian dicha rama linguística saben que Julio Casares fue el primero, en España, en tratar la fraseología a partir de su Introducción a la lexicografía moderna en 1950. De la misma manera, el primer trabajo de fraseología española fue el de Alberto Zuluaga, Introducción al estudio de las expresiones fijas publicado el año 1980. Luego, surgió el libro más destacado en este campo, Manual de fraseología española de Gloria Corpas Pastor, fruto de su tesis doctoral ${ }^{1}$, publicado en 1996. Podemos decir que estos tres trabajos marcaron el punto de arranque para el desarrollo de la fraseología en España. No podemos olvidar las aportaciones rusas, sobre todo aquellas de V. Vinogradov². Ahora bien, el MANUAL de Corpas Pastor se convirtió en una obra de referencia para todos aquellos que se interesan seriamente por el campo y desean navegar por las procelosas aguas del caudal fraseológico español ${ }^{3}$.

Desde aquel entonces y hasta el momento, aparecieron decenas de investigadores con centenares de trabajos relacionados con esta joven disciplina. Los trabajos sobre la fraseología no se tratan solamente de libros o artículos, sino también se han celebrado congresos que han podido fomentar el estudio de la

\footnotetext{
${ }^{1}$ Gloria Corpas Pastor, Un estudio paralelo de los sistemas fraseológicos del inglés y del español, Tesis doctoral, Málaga, Servicio de Publicaciones de la Universidad, 1994.

${ }^{2}$ Considerado el primer teórico que indagó en este terreno. Véase Antonia María Tristá Pérez, «Fuentes de las unidades fraseológicas. Sus modos de formación», en Zoila Victoria Carneado Moré y Antonia María Tristá Pérez (eds.), Estudios de fraseología, La Habana, Academia de Ciencias de Cuba, 1985, págs. 67-90, en especial pág. 71.

${ }^{3}$ Gloria Corpas Pastor, Manual de fraseología española, Madrid, Gredos, 1996, pág. 13.
} 
fraseología española. Además, se comenzó a aflorar un número considerable de tesis doctorales, donde se analizaron los rasgos distintivos de los fraseologismos. Todo ello ha producido un cambio de perspectiva en los estudios fraseológicos, sobre todo con el proceso del análisis de las unidades fraseológicas ${ }^{4}$. Por eso, se puede confirmar que la primera fase de esta rama se destaca como teórica. Luego, se han producido reflexiones interesantes sobre la taxonomía de dichas unidades, sus rasgos y sus características definitorias.

A lo largo de varios años en la investigación en este campo, hemos podido repasar muchos trabajos relacionados con la fraseología que tratan diversas perspectivas. Esto nos dio un impulso para pensar en llevar a cabo algunos repertorios que seguramente serían de utilidad para los nuevos investigadores que quieran trabajar en este campo. Hay que subrayar que han aparecido y siguen apareciendo trabajos y artículos de muy diversas ideas acerca de la fraseología. Por eso, la fraseología se ha convertido en una disciplina independiente ${ }^{5}$ y ha sido tratada en muchas investigaciones, bien monográficas, bien comparadas entre dos o más idiomas, sobre aspectos discursivos, estilísticos, clasificaciones teóricas, tratamiento lexicográfico, teoría y práctica de su traducción ${ }^{6}$, también su representación y su tratamiento en la lexicografía monolingüe y bilingüe ${ }^{7}$ así como de aspectos didácticos.

En este trabajo, no tratamos la fraseología en su sentido sensu stricto, sino en su sensu lato, lo que quiere decir que los trabajos que señalamos en este repertorio son aquellos que tratan la fraseología en su sentido amplio que incluye colocaciones, locuciones, enunciados fraseológicos, refranes y cualquier tipo de expresiones fijas. Cabe subrayar que la clasificación de la fraseología desde su concepción amplia ofrecida por Corpas Pastor se considera la que ha tenido más aceptación desde la aparición de dicha disciplina hasta el momento.

A continuación, presentamos una revisión bibliográfica de los principales estudios que tratan la disciplina fraseológica en cuanto a cuestiones referentes a su

\footnotetext{
${ }^{4}$ Arianna Alessandro et al., «Una experiencia didáctica en el ámbito de la fraseología contrastiva», Disponible en http://docplayer.es/16529929-Una-experiencia-didactica-en-el-ambito-de-la-fraseologia-contrastiva.html [Fecha de consulta: 17-06-2018].

${ }^{5}$ Gloria Corpas Pastor, «Corrientes actuales de la investigación fraseológica en Europa», Euskera: Trabajos y actas de la Real Academia de la Lengua Vasca, 1, 2001, págs. 21-49, en especial pág. 21.

${ }^{6} \mathrm{Fan} \mathrm{Wu}$, «Fraseología comparada del español y del chino su aplicación a la enseñanza en la clase de español como lengua extranjera», MarcoELE. Revista de Didáctica ELE, 22, 2016, págs. 1-14, en especial pág. 2.

7 Ferran Robles i Sabater, «Fuentes para el estudio del tratamiento de la fraseología en la lexicografía española monolingüe y bilingüe», Linred: Lingüística en la Red, 5, 2007, págs. 1-17, en especial pág. 1 .
} 
vertiente traductológica y contrastiva. Este tipo de trabajos puede beneficiar a los principiantes que quieran trabajar en aspectos traductológicos y contrastivos de la fraseología, así que puede servirles como guía. La principal característica de este tipo de estudios es poner entre las manos de los investigadores una información fidedigna de los trabajos realizados en el campo de la fraseología en lo que concierne a su traducción y a su estudio contrastivo, sobre todo durante los últimos cuatro décadas.

Posiblemente haya alguien que esté trabajando en algún aspecto determinado de estos dos campos y no sabe que ya, de hecho, existen trabajos que tratan el punto que él mismo está llevando a cabo, o que no sepa que haya trabajos que tratan un tema determinado que le ayude en su propio estudio, tanto en el contexto de su lengua materna como en otra lengua. Por eso, confirmamos que la falta de conocimiento de las investigaciones realizadas en esta área permite la reproducción de algunas ideas como en el trabajo de «Traductología y fraseología» de Alberto Zuluaga e incluso la repetición de algunos artículos (como en «Fraseología y traducción» de Gloria Corpas Pastor; y «Fraseología y traducción» de Julia Sevilla Muñoz, entre otros títulos casi repetidos) ${ }^{8}$.

\section{Motivos del trabajo}

Sin duda alguna, la consulta de corpus estables arroja datos enriquecedores para cualquier tipo de estudio fraseológico serio 9 . Pero resulta que no siempre es posible ubicar o saber los trabajos más relevantes que han tratado la disciplina fraseológica desde sus diversas perspectivas. Entre estas perspectivas nos llamó la atención dos aspectos de la fraseología española: el traductológico y el contrastivo.

El gran desarrollo que ha experimentado la fraseología gracias a los avances de la traductología y la linguiística contrastiva se ha reflexionado en importantes estudios reflejados en nuestro repertorio. Por eso, este artículo sirve en primer lugar para advertir a aquellos que quieran llevar a cabo una idea relacionada con alguna de estas dos perspectivas a la existencia de trabajos que se alistan en este repertorio.

El motivo sustancial que nos hizo llevar a cabo este trabajo radica en el interés que ha ejercido la disciplina de la fraseología, sobre todo durante las últimas décadas, y su interrelación con la traductología y con el estudio contrastivo. De

\footnotetext{
${ }^{8}$ Compárese en el repertorio de este trabajo.

${ }^{9}$ Gloria Corpas Pastor, «El fraseólogo internauta: cómo pasarlo pipa en la red», en Vanda Durante (ed.), Fraseología y paremiología: enfoques y aplicaciones, Centro Virtual Cervantes, Madrid, 2014, págs. 133-152, en especial pág. 151.
} 
hecho, son diversas las razones que nos hicieron realizar dicha actualización bibliográfica. Podemos destacar lo siguiente:

- Presentar una idea global para la comprensión de la diversidad de las unidades fraseológicas y su (in)traducibilidad; contribuyendo a dar una imagen sobre el estado de la cuestión acerca de la fraseología en enfoques contrastivos.

- Apoyar la aproximación de los estudiosos en este campo en cuanto a su traducción, así como estimular el interés en la necesidad de su verificación dentro del área de su contrastividad.

- Promover el estudio en el carácter interdisciplinar de la esfera fraseológica en el seno del área de traducción, ayudando a los nuevos investigadores a familiarizarse con la terminología relacionada con esta disciplina.

- Presentar un acercamiento para los estudios de repertorios bibliográficos en lo que atañe a la fraseología y, al mismo tiempo, responder a una necesidad de actualización bibliográfica que resulta útil para los investigadores de la traducción y la comparación fraseológica.

- Ofrecer una serie de referencias para la investigación teórica y práctica de la fraseología en el ámbito traductológico y contrastivo a través de poner de relieve la relación de la fraseología con otras ramas lingüísticas.

- Identificar las principales perspectivas traductológicas y contrastivas llevadas a cabo sobre la fraseología con el fin de orientarles a los investigadores sobre lo realizado hasta el momento y abrirles, a la vez, nuevas vías de investigación.

\section{Metodología}

Los trabajos que presentamos en este repertorio son publicados entre las fechas $1977-2017^{10}$. Nuestra metodología reside en dividir dicho repertorio en tres partes esenciales. La primera abarca los trabajos que tratan la disciplina fraseológica desde su aspecto traductológico. La segunda se trata de una sección que abarca el tratamiento de la fraseología desde una perspectiva contrastiva. La última presenta una serie de trabajos que tienen una mezcla de las dos temáticas anteriores.

Por lo tanto, estas tres secciones incluyen un amplio abanico de investigadores que han presentado diversos enfoques y aplicaciones en lo que se refiere a la metodología de la traducción de la fraseología y su estudio contrastivo. Por lo tanto, el repertorio que pretendemos llevar a cabo no es general, sino especializado que se ocupa de los dos aspectos sobre los cuales se trata nuestro artículo.

${ }^{10}$ Como habíamos indicado, este repertorio cubre los principales trabajos durante las últimas cuatro décadas. 
Creemos que estos dos aspectos son los primeros en impresionar a cualquier investigador que quiera trabajar en el campo fraseológico. Nos gustaría esclarecer que hemos preferido combinar estos dos aspectos en un solo trabajo porque tienen un vínculo interrelacionado. La traducción tiene que ver con el tema de comparación y viceversa. Por lo tanto, aquellos que trabajan en cualquiera de ellos, inevitablemente necesitan saber qué se publicó en el otro lado.

La agrupación de esta serie de trabajos ha sido gracias a lo que se nos proporcionó a lo largo de varios años de investigación en dicha rama linguiística. Personalmente, mi formación en la Universidad Complutense de Madrid durante mi doctorado y luego durante la estancia de posdoctorado, me facilitó ver investigaciones relevantes con el tema de este artículo. La mayoría de los libros publicados y las revistas especializadas que he examinado ha hecho posible la consulta de fuentes bibliográficas sobre las que se basa la parte esencial de este trabajo.

Antes de presentar el repertorio bibliográfico de nuestro estudio, conviene echar una vista breve sobre la relación fraseología-traducción y fraseología contrastiva, dos ejes de este trabajo.

\section{Fraseología-traducción}

No cabe la menor duda de que la característica principal de la traducción es para comunicar; para traspasar la barrera de incomunicación debida a la diferencia linguística y cultural ${ }^{11}$; por lo que se puede decir que la traducción posee, en primer lugar, un propósito comunicativo. Si podemos decir esto en general, lo es más cuando se traduce estructuras fraseológicas de una lengua a otra. Esto es porque las unidades fraseológicas se caracterizan por algunos elementos, como la de fijación e idiomaticidad $^{12}$, elementos que dificultan su proceso de traducción. Estos elementos añaden dificultad y complejidad, no solamente para los traductores, sino también para los que usan dichas estructuras en el proceso de la enseñanza de un idioma extranjero.

Por eso, una de las grandes dificultades para el traductor es la traducción de las unidades fraseológicas, ya que el problema radica en su estructura tan particular $\mathrm{y}$, al mismo tiempo, se debe al poco número de diccionarios dedicados a esta faceta lingüística; ya que el sentido global de dichas unidades no se deduce del

\footnotetext{
${ }^{11}$ Amparo Hurtado Albir, Traducción y traductología. Introducción a la traductología, Madrid, Cátedra, 2007, pág. 25.

12 Alberto Zuluaga Ospina, «Traductología y Fraseología», Paremia, 8, 1999, págs. 537-549, en especial pág. 543.
} 
significado de los elementos que las componen, porque poseen un sentido idiomático que no se entiende a partir de una traducción literal.

En este sentido, existe un gran problema en cuanto a su traducibilidad. Hay opiniones diferentes que vacilan entre la posibilidad, la dificultad y la imposibilidad de su traducción. Por eso, el hecho de buscar unidades fraseológicas de una lengua de origen en una lengua meta pasa por algunas técnicas de traducción y por una búsqueda de equivalencias que se exponen en la fase de reformulación del texto.

Aunque habíamos tratado los grados de equivalencia en trabajos anteriores, aquí nos limitamos a ofrecer breves alusiones a los cuatro niveles de equivalencia translémica $^{13}$ :

- Equivalencia total: donde el significado idiomático y la estructura morfológica concuerdan tanto en la lengua de partida como en la lengua de llegada.

- Equivalencia parcial: se da cuando las estructuras fraseológicas no coinciden por completo en las dos lenguas de partida y de llegada, ofreciendo diferencias denotativas.

- Equivalencia aparente: puede considerarse cuando los componentes de alguna unidad fraseológica en ambas lenguas parecen ser iguales debido a coincidencias morfológicas y lexémicas, pero a nivel semántico no tienen ningún tipo de equivalencia. Esto es lo que origina los llamados falsos amigos que representan un cierto problema de traducción ${ }^{14}$.

- Equivalencia nula: aparece cuando no existe una unidad fraseológica en la lengua meta para una otra unidad existente en la lengua de origen.

Por eso, no es de extrañar que repetidas veces leemos que el hecho de traducir las unidades fraseológicas se trata de un verdadero desafío. El problema mayor, a nuestro parecer, es poder identificarlas, interpretar su significado semántico-discursivo y buscar su equivalente en la lengua meta. Los trabajos que tratan el aspecto traductológico de la fraseología, reflejados en el repertorio de nuestro trabajo, ofrecen con mucho detalle las estrategias de traducciones y equivalencias de las diferentes esferas fraseológicas.

${ }^{13}$ Gloria Corpas Pastor (ed.), «Acerca de la (in)traducibilidad de la fraseología», en Diez años de investigación en fraseología: análisis sintáctico-semánticos, contrastivos y traductológicos, Madrid/Fráncfort del Meno, Iberoamericana/Vervuert, 2003, págs. 275-310, en especial págs. 302305.

${ }^{14}$ Esto nos llevó a llevar a cabo un artículo relacionado con los falsos cognados o los llamados falsos amigos. Véase Tarek Shaban Mohammad Salem, «Los falsos amigos a nivel fraseológico entre el español y el árabe a través de algunos ejemplos», Journal of Faculty of Language and translation, 10, El Cairo, 2016, págs. 237-268. 
A continuación, vamos a ofrecer los trabajos que componen el repertorio bibliográfico para el estudio traductológico de la fraseología española.

Aguilar-Amat, Anna, «Caracterización sintáctica de los idiomatismos y propuestas de "Parser" para un sistema de traducción automática», en María Ángeles Álvarez Martínez (ed.), Actas del Congreso de la Sociedad Española de Lingüística. XX Aniversario, Madrid, Gredos, 1990, págs. 824833.

Albaladejo-MartíNEZ, Juan Antonio, «Fraseología especializada en Traducción General: una propuesta didáctica», en Pedro Mogorrón y Fernando Navarro (eds.), Fraseología, didáctica y traducción, Fráncfort del Meno, Peter Lang, 2015, págs. 273-290.

AlOUSQUE, Isabel, «La traducción de las expresiones idiomáticas marcadas culturalmente», Revista de Lingüística y Lenguas Aplicadas, 5, 2010, págs. 133-140.

ANTONELla SARDELli, Maria, «La fraseología en las clases de traducción: aproximación metodológica y aplicaciones prácticas», en María Isabel González Rey (coord.), Didáctica y traducción de las unidades fraseológicas, Santiago de Compostela, Publicaciones de la Universidad, 2014, págs. 199-212.

ASSAM, Bouazza, «Notas sobre la concepción de diccionarios de fraseología para traductores», en Luis González y Pollux Hernúñez (coords.), Las palabras del traductor: Actas del II Congreso Internacional el español lengua de traducción, Toledo Esletra, Bruselas, 2004, págs. 293-306.

BANGo DE LA CAMPA, Flor María, «Sobre la (in)equivalencia de las UFs: el caso de las 'locuciones'», Anales de Filología Francesa, 12, 2003-2004, págs. 2138.

Cobeta Melchor, María del Mar, «La comunicación intercultural: El problema de la traducción de paremias», en Luis Iglesias Rábade y Paloma Núñez Pertejo (eds.), Estudios de Lingüística contrastiva, Santiago de Compostela, Ediciones de la Universidad, 1999, págs. 165-172.

Cobeta Melchor, María del Mar, «Paremiología y traducción», en Laura Cruz García et al., (coords.), Actas de las II Jornadas de Jóvenes Traductores, Gran Canaria, Ediciones de la Universidad, 2002, págs. 107-117.

CORPAS PASTOR, Gloria (ed.), «Acerca de la (in)traducibilidad de la fraseología», en Diez años de investigación en fraseología: análisis sintáctico-semánticos, 
contrastivos y traductológicos, Madrid/Fráncfort del Meno, Iberoamericana/Vervuert, 2003, págs. 275-310.

CORPAS PAStor, Gloria (ed.), Las Lenguas de Europa. Estudios de Fraseología, Fraseografía y Traducción, Granada, Editorial Comares, 2000.

Corpas Pastor, Gloria y Moreno Ortiz, Antonio, «Diseño de una base de datos fraseológica para la traducción asistida por ordenador (TAO)», en Carlos Martín Vide (ed.), Actas del XI Congreso de Lenguajes Naturales de Lenguajes Formales, Barcelona, Promociones y Publicaciones Universitarias, 1995, págs. 389-396.

CORPAS PASTOR, Gloria, «Fraseología y traducción», en Vicent Salvador y Adolf Piquer (eds.), El discurs prefabricat. Estudis de fraseologia teòrica i aplicada, Castelló de la Plana, Publicacions de la Universitat Jaume I, 2000, págs. 107138.

CORPAS PASTOR, Gloria, «La creatividad fraseológica: efectos semánticopragmáticos y estrategias de traducción», Paremia, 10, 2001, págs. 67-78.

CORPAS PASTOR, Gloria, «La traducción de unidades fraseológicas: técnicas y estrategias», en Isabel de la Cruz Sabanillas et al. (eds.), La lingüística aplicada a finales del siglo XX. Ensayos y propuestas, Alcalá de Henares, Publicaciones de la Universidad, 2001, págs. 779-787.

Crida Álvarez, Carlos Alberto y Papageorgíou, Anthí, «Miguel Delibes en griego moderno. La traducción de fraseologismos y paremias», Paremia, 20, 2011, págs. 19-28.

CridA Álvarez, Carlos Alberto, «La traducción al español de las fórmulas rutinarias desiderativas del griego moderno», en Julia Sevilla Muñoz (ed.), Fraseología y Léxico. Un enfoque contrastivo, Lugo, AXAC, 2104, págs. 229-258.

DENGLER GASSIN, Roberto, «Un ejemplo de la imprescindible labor del traductor: Fraseología y Traducción», en Elena Sánchez Trigo y Díaz Fauces (eds.), Traducción y Comunicación, Vigo, Ediciones de la Universidad, 2002, págs. 27-33.

DOBROVOL'SKIĬ, Dmitriï, «Acerca de la equivalencia transligüística de los fraseologismos», en Juan de Dios Luque Durán y Antonio Pamies Bertrán (eds.), La creatividad en el lenguaje: colocaciones idiomáticas y fraseología, Granada, Método, 2005, págs. 359-379. 
FRAILE VICENTE, Esther (ed.), «La fraseología y las expresiones idiomáticas y la traducción de las expresiones idiomáticas», en Las expresiones idiomáticas de la economía en inglés y español. Propuesta para un correcto tratamiento terminográfico, Valladolid, Publicaciones de la Universidad, 2007, págs. 97-174.

Gálvez Vidal, Alba María y Navarro Coy, Marta, «¿Es Carmen la misma persona cuando habla inglés? La traducción de unidades fraseológicas en Cinco horas con Mario», en Germán Conde Tarrío et al. (eds.), Enfoques actuales para la traducción fraseológica y paremiológica: ámbitos, recursos y modalidades, Madrid, Instituto Cervantes, 2015, págs. 129-142.

GÁlvez VIDAL, Alba María, «Las paremias de Carmen y su traducción al inglés: un estudio paremiológico de Cinco horas con Mario, de Miguel Delibes», Paremia, 23, 2014, págs. 45-55.

GonZÁlez ReY, María Isabel (coord.), Didáctica y traducción de las unidades fraseológicas, Santiago de Compostela, Publicaciones de la Universidad, 2014.

GUTIÉRREZ DÍEZ, Francisco, «Idiomaticidad y traducción», Cuadernos de Filología inglesa, 4, 1995, págs. 27-42.

LEIVA RoJo, Jorge, «Fraseología, traducción y control de calidad: acerca de la (im)posibilidad de armonización de parámetros para la evaluación», HEL: Histoire Épistémologie Langage, 2, 2012, págs. 89-105.

LEIVA RoJO, Jorge, «Propuesta de formulario electrónico para la revisión de unidades fraseológicas traducidas», Educatio Siglo XXI, 2, 2013, págs. 277296.

LOZANO, C. W., «Aproximación al problema de las expresiones idiomáticas y su traducción», Sendebar, 3, 1992, págs. 141-156.

LUQUE DuRÁN, Juan de Dios, «Cómo enseñar a colocar en otra lengua. Sistematicidad y particularidad de las construcciones colocacionales», en F. García Marcos et al. (eds.), Traducción, cultura e inmigración. Reflexiones interdisciplinares, Granada, Editorial Atrio, 2004, págs. 39-49.

LUQUE DuRÁN, Juan de Dios, «Lingüística y traducción. El estudio de las colocaciones desde un planteamiento traductológico y tipológico lingüístico», en Emilio Ortega Arjonilla y María García Peinado (eds.), Actas del XI Simposio Internacional Traducción, Texto e Interferencias. La 
investigación y la práctica profesional de la Traducción e Interpretación en los albores del siglo XXI, Málaga, Atrio, 2003, págs. 299-312.

Mahmoud Ahmed, Yasmeen, «El Lazarillo de Tormes en árabe: la traducción de paremias y locuciones», TRANS: Revista de traductología, 17, 2013, págs. 117-138.

MAYORAL ASENSIO, Roberto, «La traducción de las referencias culturales», Sendebar, 11, 2000, págs. 67-88.

MENDONÇA DE LIMA, Lucielena, «La traducción de los modismos en la enseñanza del español como lengua extranjera», en Kira Alonso et al. (dirs.), El español como lengua extranjera: del pasado al futuro. Actas del VIII Congreso Internacional de ASELE, Alcalá de Henares, Publicaciones de la Universidad, 1998, págs. 569-574.

MiRA Álvarez, Germán Darío, «La equivalencia en la traducción de las unidades fraseológicas. Un estudio empírico», Íkala: Revista de lenguaje y cultura, 27, 2011, págs. 105-128.

Mogorrón Huerta, Pedro et al. (eds.), Fraseología, Opacidad y traducción, Franfurt am Main, Peter Lang, 2013.

MORVAY, Károly, «La fraseología en las traducciones polacas del Quijote», Annales Universitatis Scientiarum Budapestinensis de Rolando Eötvös Nominatae. Sectio Linguistica, IX, 1978, págs. 227-233.

ORERO, Pilar, «La traducción de wellerismos», Quaderns. Revista de traducción, 5, 2000, págs. 123-133.

PAMIES BERTRÁn, Antonio (ed.), De lingüística, traducción y léxico-fraseología. Homenaje a Juan de Dios Luque, Granada, Editorial Comares, 2013.

PONCE MÁrquEZ, Nuria, «El arte de traducir expresiones idiomáticas: la finalidad de la funcionalidad», Hermeneus: Revista de Traducción e Interpretación, 13, 2011, págs. 1-14.

RICHART MARSET, Mabel, «Las unidades fraseológicas y su resistencia a la traducción», Foro de Profesores de E/LE, 4, 2008, págs. 1-10.

RICHART MARSET, Mabel, «Los problemas de la traducción de las unidades fraseológicas como motor de la enseñanza de una segunda lengua», en Actas del I Congreso Internacional de Lengua, Literatura y Cultura Española: la didáctica de la enseñanza para extranjeros, Onda, JMC, 2007, págs. 395-404. 
RICHART MARSET, Mabel, Fraseología y traducción: una semiótica difusa, Valencia, Publicaciones de la Universidad, 2009.

SANTAMARÍA PÉREZ, María Isabel, «Unidades fraseológicas: análisis cualitativo y cuantitativo de los equivalentes de traducción en el diccionario bilingüe», en María Paz Battaner y Janet Ann DeCesaris (coords.), De lexicografia: actes del I Symposium Internacional de Lexicografia, Barcelona, Universitat Pompeu Fabra, Institut Universitari de Linguiística Aplicada, 2004, págs. 755765.

SERRANO LuCAS, Lucía Clara, «Metodología para la enseñanza de la fraseología en traducción: la ficha fraseológica como tarea final», Paremia, 19, 2010, págs. 197-206.

SeVILla Muñoz, Julia y BuRREL Argüís, Mercedes, «La traducción en las colecciones paremiográficas plurilingües», Livius, 5, 1993, págs. 189-198.

Sevilla Muñoz, Julia y Sevilla Muñoz, Manuel, «La técnica actancial en la traducción de refranes y frases proverbiales», El Trujamán, 2004. Disponible en: http://cvc.cervantes.es/trujaman/anteriores/noviembre_04/08112004.htm.

SeVIlla Muñoz, Julia y Sevilla MuÑoz, Manuel, «La técnica sinonímica en la traducción de refranes y frases proverbiales», El Trujamán, 2005. Disponible en: http://cvc.cervantes.es/trujaman/anteriores/marzo_05/03032005.htm [Fecha de consulta: 30-06-2018].

SeVIlla MuÑoz, Julia y SeVILla MuÑOZ, Manuel, «La técnica temática en la traducción de refranes y frases proverbiales», El Trujamán, 2004, Disponible en: https://cvc.cervantes.es/trujaman/anteriores/noviembre_04/24112004.htm [Fecha de consulta: 11-05-2018].

SEVILla MuÑoz, Julia, «Fraseología y traducción», Thélème: Revista complutense de estudios franceses, 12, 1997, págs. 431-440.

SEVILla MuÑoz, Julia, «La técnica hiperonímica en la traducción de refranes y frases proverbiales», El Trujamán, 2011. Disponible en https://cvc.cervantes.es/trujaman/anteriores/marzo_11/10032011.htm [Fecha de consulta: 18-3-2018].

SeVILla MuÑoz, Manuel, «Condicionantes textuales en la traducción fraseológica y paremiológica», Paremia, 24, 2015, págs. 95-107. 
SEVILla MuÑOZ, Manuel, «Las unidades fraseológicas en la traducción literaria (el caso de las locuciones en Las ratas de Miguel Delibes)», Verba Hispanica, XXI, 2013, págs. 101-116.

SEVILla MuÑOZ, Manuel, «Opacidad y motivación de las unidades fraseológicas en la didáctica de traducción», en Pedro Mogorrón Huerta et al. (eds.), Fraseología, opacidad y traducción, Frankfurt am Main, Peter Lang, 2013, págs. 179-192.

SEVILLA, M., «Estrategias didácticas para la interpretación de unidades fraseológicas en el aula de Fraseología y Traducción», en Pedro Mogorrón Huerta (coord.), Comunicación a las III Jornadas internacionales de fraseología contrastiva: fraseología opacidad y traducción, Alicante, Publicaciones de la Universidad, 2010.

TimofEEVA, Larissa, «Sobre la traducción de la fraseología: un enfoque pragmático», Interlingüística, 17, 2006, págs. 1029-1038.

TimofEEVA, Larissa, «Sobre la traducción fraseológica», ELUA, 26, 2012. págs. 405-432.

TimofeEVA, Larissa, Acerca de los aspectos traductológicos de la fraseología española, Tesis doctoral, Alicante, Publicaciones de la Universidad, 2008.

ULRICH, Miorita, «Fraseología y traducción: a propósito de los welerismos», en Julio César Santoyo (ed.), Translation across cultures: La traducción entre el mundo hispánico y anglosajón. Relaciones lingüísticas, culturales y literarias. Actas del XI Congreso AEDEAN, León, Universidad de León, 1989, págs. 199-206.

ZuluagA OSPINA, Alberto, «Análisis y traducción de unidades desautomatizadas», PhiN, 16, 2000-2001, págs. 67-83.

ZuluagA, Alberto, «Traductología y fraseología», Paremia, 8, 1999, págs. 537549.

\section{Fraseología contrastiva}

La fraseología contrastiva tiene como objetivo general determinar las diferencias y semejanzas entre los sistemas fraseológicos, así como la búsqueda de correspondencias interlingüísticas entre dos o más idiomas, esto es, correspondencias que se construyen entre una unidad fraseológica de una lengua dada y otra unidad de otra lengua con la cual se compara. Al respecto, hay estudios que comparan determinados aspectos entre el español y otras lenguas como el alemán, el italiano, el portugués, el inglés, el árabe, etc.; y que en su conjunto 
estudian las relaciones contraídas de los universos fraseológicos pertinentes de cada lengua.

Dado que el aspecto traductológico de la fraseología es tan estrecho con el aspecto contrastivo, dentro de este ámbito, se puede plasmar una escala gradual que va desde la equivalencia nula hasta la equivalencia total pasando por la equivalencia parcial en mayor o menor medida ${ }^{15}$.

Por lo tanto, nuestro trabajo se trata de una orientación que muestra que, hasta el momento, hay que hacer más esfuerzo para más estudios que aborden de forma sistemática el tema de la traducción fraseológica y su relación con los aspectos contrastivos, sobre todo, de las implicaciones de la existencia de equivalentes pragmáticos. Asimismo, aludimos a que no son muchos los trabajos que tratan procesos conceptuales de naturaleza metafórica. Esto quiere decir que, aunque ya pasados cuatro décadas de investigación en la esfera fraseológica, queda mucho por investigar en este terreno no restringido.

En lo siguiente, vamos a ofrecer los trabajos que componen el repertorio bibliográfico para el estudio contrastivo de la fraseología española.

AliJo JiMÉNEZ, Isabel y Al JALLAD, Nader, «Colocaciones comparativas árabes», en Juan de Dios Luque Durán y Antonio Pamies Bertrán (eds.), La creatividad en el lenguaje: colocaciones idiomáticas y fraseología, Granada, Granada Lingvística, 2005, págs. 399-408.

Almela PÉreZ, Ramón, et al. (eds.), Fraseología contrastiva: con ejemplos tomados del alemán, español, francés e italiano, Murcia, Publicaciones de la Universidad, 2005.

Álvarez BENITO, Gloria, «Estudio contrastivo inglés-español de las frases idiomáticas o lexías compuestas comparativas», en Martínez Vázquez (ed.), Gramática contrastiva inglés-español, Huelva, Ediciones de la Universidad, 1996, págs. 297-308.

Amigot CAstillo, Laura y OlzA, Inés, «Prosodia de las fórmulas rutinarias expresivas: notas contrastivas alemán-español e implicaciones en la enseñanza de segundas lenguas», en María Isabel González Rey (coord.), Didáctica y traducción de las unidades fraseológicas, Santiago de Compostela, Servizo de Publicacións e Intercambio Científico 2014, págs. 115-130.

15 María Jesús Leal Riol, «Contraste fraseológico: Similitudes y diferencias existentes entre las unidades fraseológicas del inglés y del español», ES: Revista de filología inglesa, 29, 2008, págs. 103-116, en especial pág. 108. 
ANDRADES MORENO, Arsenio, Estudio contrastivo de unidades fraseológicas especializadas (EFE) en un corpus comparable bilingüe de contratos de derecho civil en lengua inglesa y española, Tesis doctoral, Madrid, Universidad Complutense de Madrid, 2014.

ARRIANDIAGA, Teresa, «Reflexiones sobre los modismos en inglés y en español: estudio comparativo», en José María Ruiz et al. (eds.), XI Congreso Nacional de Lingüística Aplicada, Valladolid, Ediciones de la Universidad, 1995, págs. 103-108.

BARAN À NKOUM, Patricia, Estudio contrastivo español-francés de las locuciones verbales somáticas relativas a la cabeza, Madrid, Universidad Complutense de Madrid, 2015.

BArgalló Escrivá, Maria y Ginebra Serrabou, Jordi, «Doctrina sobre idiomaticidad y fraseología en algunas gramáticas catalanas y españolas de los siglos XVIII y XIX», en Esparza Torres et al, (eds.), Estudios de Historiografía Lingüística, Hamburgo, Helmut Buske, 2001, págs. 789-804.

CALERo FERnÁNDEZ, María Ángeles, «Acerca de Dios y del demonio en la fraseología española y catalana», Gerd Wotjak (ed.), Estudios de fraseología y fraseografía del español actual, Frankfurt, Iberoamericana, 1998, págs. 155-194.

CALERo FernándeZ, María Ángeles, «Jesús y María en la fraseología religiosa del español y catalán», Paremia, 8, 1999, págs. 77-84.

CAlero FERnÁndeZ, María Ángeles, «Personajes y episodios bíblicos en las locuciones y frases hechas del español y catalán», Paremia, 9, 2000, págs. 49-60.

CARBONELl BASSET, Delfín, «Lexicografía fraseológica bilingüe: castellano e inglés», en Gloria Corpas Pastor (ed.), Las lenguas de Europa. Estudios de fraseología, fraseografia y traducción, Granada, Comares, 2000, págs. 355365.

CASAdo Conde, María Leonisa, ¡Se dice pronto! 1.150 expresiones, modismos y frases hechas en castellano y su versión equivalente en inglés, francés e italiano, Madrid, Ediciones Internacionales Universitarias, 2002.

CoDITA, Viorica, «Estudio comparativo de las locuciones prepositivas en Calila e Dimna y El Conde Lucanor. En torno a las unidades con en y por», en Elena Carmona Yanes y Santiago del Rey Quesada (coords.), Id est, loquendi peritia. Aportaciones a la Lingüística Diacrónica de los Jóvenes 
Investigadores de Historiografía e Historia de la Lengua Española, Sevilla, Publicaciones de la Universidad, 2011, págs. 203-214.

CORBACHO SÁNCHEZ, Alfonso, «Apuntes sobre fraseología en torno al vino como componente base en las lenguas alemana y española: un estudio lingüístico contrastivo», Babel-A.F.I.A.l.: Aspectos de filología inglesa y alemana, 13, 2004, págs. 111-128.

CORPAS PASTOR, Gloria, «Criterios generales de clasificación del universo fraseológico de las lenguas, con ejemplos en español y en inglés», en Manuel Alvar Ezquerra y Gloria Corpas Pastor (eds.), Diccionarios, frases, palabras, Málaga, Publicaciones de la Universidad, 1998, págs. 157-187.

CORPAS PASTOR, Gloria, «Grados de equivalencia translémica de las locuciones en inglés y español», en R. J. Sola, L. A. Lázaro y J. A. Gurpegui (eds.), Actas del XVIII Congreso de AEDEAN, Alcalá de Henares, Publicaciones de la Universidad, 1997, págs. 335- 341.

CORPAS PASTOR, Gloria, Estudio contrastivo de las colocaciones en inglés y en español. Su tratamiento lexicográfico, con especial referencia al tipo $A+S / S+A$, Málaga, Servicio de Publicaciones de la Universidad, 1989.

CORPAS PASTOR, Gloria, Un estudio paralelo de los sistemas fraseológicos del inglés y el español, Tesis doctoral, Madrid, Universidad Complutense de Madrid, 1994.

FERnÁNDEZ DE LA TORRE MADUEÑO, María Dolores, «Expresión del carácter femenino en unidades fraseológicas inglesas y españolas con woman y mujer», en Carmen Valero Garcés e Isabel de la Cruz Cabanillas (eds.), Nuevas tendencias y aplicaciones de la traducción. Encuentros en torno a la traducción, Alcalá, Publicaciones de la Universidad, 1998, págs. 187193.

FERnÁNDEZ-VillanUEVA JANÉ, Marta, «Consideraciones sobre los estudios contrastivos de fraseologismos», Revista de Filología Alemana, 1, 1993, págs. $145-154$.

GARCÍA-PAGE SÁNCHEZ, Mario, «Más sobre la comparativa fraseológica en español», LEA, XVIII/1, 1996, págs. 49-77.

GARCÍA-PAGE SÁNCHEZ, Mario, «Problemas en el empleo de la fraseología española por hablantes extranjeros: la violación de restricciones», en Francisco Javier Grande Alija et al. (coords.), Actuales tendencias en la enseñanza del 
español como lengua extranjera II: Actas del VI Congreso Internacional de ASELE, 1996, págs. 155-162

GómEZ LÓPEZ, Elisa, «O campo semántico dos animais na fraseoloxía galega, española, inglesa e francesa. Estudio comparativo», Viceversa, 4, 1998, págs. 79-101.

GonZÁleZ REY, María Isabel, «La noción de 'hápax' en el sistema fraseológico francés y español», en Ramón Almela et al. (eds.), Fraseología contrastiva con ejemplos tomados del alemán, español, francés e italiano, Murcia, Ediciones de la Universidad, 2005, págs. 313-328.

GonZÁleZ RoYo, Carmen, «La afinidad del español y el italiano: sobre fraseología. La problemática de la afinidad entre el español y el italiano desde la fraseología contrastiva. A partir de Corinei, un corpus oral de interlingua español/italiano», RedELE, 2011. Disponible en http://www.educacion.gob.es/redele/Biblioteca-

Virtual/2011/NumerosEspeciales/Napoles2011.html [Fecha de consulta: 1701-2018].

GuILlÉn MONJE, Gonzalo, «Análisis y correspondencia intercultural ruso-español de unidades fraseológicas con nombres propios», Mundo eslavo: revista de cultura y estudios eslavos, 1, 2002, págs. 81-88.

GuILlÉN MonJE, Gonzalo, «Fraseología contrastiva hispano-rusa: propuesta para la creación de un diccionario bilingüe fraseológico», Interlingüística, 13, 2002, págs. 321-334.

GuILlÉn MONJE, Gonzalo, Fraseología contrastiva ruso-española: análisis de un corpus bilingüe de Somatismos, Tesis doctoral, Granada, Ediciones de la Universidad, 2004.

KAREEM SAGBAN, Mushtaq, La fraseología comparada del español y del árabe de Irak: su aplicación a la enseñanza de las unidades fraseológicas en el aula de E/LE, Tesis doctoral, Granada, Editorial de la Universidad, 2010.

LARReta Zulategui, Juan Pablo, «Fraseografía alemán-español: aplicaciones de la semántica cognitiva y de la fraseología contrastiva», Anuari de filologia, Secció A, Filologia anglesa i alemana, 9, 1998-2000, págs. 31-48.

LARReTA Zulategui, Juan Pablo, «Fraseología contrastiva alemán-español: hacia un estudio onomasiológico/ideográfico», en Tradición e innovación en los estudios de lengua, literatura y cultura alemanas en España, Sevilla, Kronos Universidad, 1998, págs. 461-472. 
Larreta Zulategui, Juan Pablo, «Sistemas de signos como fuentes de formación de fraseologismos del alemán y el español», Philologia Hispalenses, 12, 1998, págs. 21-36.

LARReta Zulategui, Juan Pablo, Fraseología contrastiva del español y del alemán. Teoría y práctica a partir de un corpus bilingüe de somatismos, Frankfurt am Main, Peter Lang, 2001.

LEIVA RoJO, Jorge, «Fraseología contrastiva y registro coloquial: esquemas sintácticos y valores semánticos en locuciones adverbiales», en María Isabel González Rey (coord.), Didáctica y traducción de las unidades fraseológicas, Santiago de Compostela, Servizo de Publicacións e Intercambio Científico 2014, págs. 53-73.

LIVERANI, Elena, «Apuntes de fraseología contrastiva a propósito del zoónimo gato», en Félix San Vicente Santiago y Maria Vittoria Calvi, Didáctica del léxico y nuevas tecnologías, Viareggio, Mauro Baroni editore, 2003, págs. $112-138$.

LóPez RoIG, Cecilia, Aspectos de fraseología contrastiva (alemán y español en el sistema y en el texto), Frankfurt am Main, Peter Lang, 2002.

LuQue Durán, Juan de Dios y SIKANOVA, Natalia, «Estudio comparado de las unidades fraseológicas en español y en ruso: apuntes para una tipología», en Luque Durán Juan de Dios y Antonio Pamies Bertrán (eds.), Primeras Jornadas sobre Estudio y Enseñanza del Léxico, Granada, Ediciones de la Universidad, 1995, págs. 225-231.

LUQUE TORO, Luis, «La fraseología en el diccionario: métodos y contraste con el inglés», en Juan de Dios Luque Durán y Francisco José Manjón Pozas (eds.), Estudios de lexicología y creatividad léxica, III Jornadas internacionales sobre estudio y enseñanza del léxico, Granada, Método ediciones, 1997, págs. 247254.

Márquez LinARes, Carlos y Moreno OrTIZ, Antonio, «Fraseología comparada mediante el uso de córpora textuales: El caso de 'Mano'/'Hand», en A. Yanguas y F. J. Salguero (eds.), Estudios de lingüística Descriptiva y Comparada, Sevilla, Publicaciones de la Universidad, 1999, págs. 291-304.

MARTÍN MingORANCE, Leocadio, «Las unidades sintagmáticas verbales en inglés y en español. Metodología de análisis», en Actas del I Congreso Nacional de la Asociación Española de Lingüística Aplicada, Madrid, AESLA-SGEL, 1983, págs. 211-220. 
Mellado Blanco, Carmen, «Convergencias idiomáticas en alemán y español desde una perspectiva cognitiva», en Juan de Dios Luque Durán y Antonio Pamies Bertrán (eds.), La creatividad en el lenguaje: colocaciones idiomáticas y fraseología, Granada, Método, 2005, págs. 73-96.

Mellado Blanco, Carmen, «Formas estereotipadas de realización no verbal en alemán y español: los cinegramas desde un enfoque contrastivo-histórico», en Gloria Corpas Pastor (ed.), Las lenguas de Europa. Estudios de fraseología, fraseografía y traducción, Granada, Comares, 2000, págs. 389-410.

Mellado Blanco, Carmen, «Fraseologismos alemanes y españoles del campo de las emociones», Paremia, 6, 1997, págs. 383-388.

Mellado Blanco, Carmen, «La Biblia como fuente de idiomaticidad. Pretextos y contextos en alemán y español», en Juan de Dios Luque Duran y Antonio Pamies Bertrán (eds.), Interculturalidad y lenguaje I: El significado como corolario cultural, Granada, Granada Lingvistica, 2007, págs. 99-108.

Mellado Blanco, Carmen, «La estructura idiomática del alemán y el español. Un estudio cognitivo a partir de un corpus onomasiológico. Algunos apuntes sobre pragmática», en Pablo Cano López et al. (eds.) Actas del XXXIX Simposio Internacional de la Sociedad Española de Lingüística (SEL), Santiago de Compostela, Publicaciones de la Universidad, 2010, págs. 7791.

Mellado Blanco, Carmen, «La gramaticalización de las restricciones y preferencias de uso de las unidades fraseológicas del español y alemán desde un enfoque cognitivo-pragmático», en Inés Olza Moreno y Elvira Manero Richard (coords.), Fraseopragmática, Berlin, Franke and Time, 2013, págs. 303-334.

Mellado Blanco, Carmen, «Parámetros específicos de equivalencia en las unidades fraseológicas (con ejemplos del español y el alemán)», Revista de Filología, 33, 2015, págs. 153-174.

MolinA GARCÍA, Daniel, Fraseología bilingüe: un enfoque lexicográficopedagógico, Granada, Comares, 2006.

MoRvaY, Károly, «Harri batez bi kolpe. Cuestiones de fraseología comparada», Euskera, 3, 1996, págs. 719-767. 
MURA, Giovanna Ángela, Las unidades fraseológicas en el registro coloquial: estudio contrastivo español-italiano, Tesis doctoral, Madrid, Universidad Complutense de Madrid, 2012.

NAVARro, Carmen, «Fraseología contrastiva del español y el italiano (análisis de un corpus bilinguie)», Tonos digital: Revista electrónica de estudios filológicos, $\quad$ 13, 2007. Disponible en: https://www.um.es/tonosdigital/znum13/secciones/estudios_U_fraseologia. htm [Fecha de consulta: 17-01-2018].

NAVARro, Carmen, Aspectos de fraseología contrastiva: español-italiano, Verona, Fiorini, 2008.

NiKolÁEVA, Joulia Vadímovna, Particularidades lógico-semióticas de proverbios españoles e italianos (investigación contrastiva), Tesis doctoral, San Petersburgo, Universidad Estatal Pedagógica, 2000.

NúÑEZ RoMÁN, Francisco, «La expresión fraseológica de la ira en italiano y español: un estudio cognitivo», Philologia Hispalensis, 28, 2014, págs. 213233.

PAMIES BERTRÁN, Antonio (eds.), «Comparación estereotipada y colocación en español y francés», Paremiología y herencia cultural, Granada, Granada Lingvística, 2011, págs. 469-484.

PAMIES BERTRÁN, Antonio et al, «Fraseología en la borrachera en guaraní y en español», Paremia, 13, 2004, págs. 51-64.

PAMIES Bertrán, Antonio y Luque Durán, Juan de Dios (eds.), Trabajos de lexicografía y fraseología contrastiva, Granada, Método Ediciones, 2000 .

PAMIES BERTRÁN, Antonio, «La comparación estereotipada en español y en francés», en Juan de Dios Luque Durán y Antonio Pamies Bertrán (eds.), La creatividad en el lenguaje: colocaciones idiomáticas y fraseología, Granada, Método, 2005, págs. 469-484.

PENADÉS MARTÍNEZ, Inmaculada, «Análisis cognitivo de locuciones somáticas nominales del español, catalán y portugués», en Antonio Moreno Sandoval (coord.), El valor de la diversidad (meta) lingüística: Actas del VIII congreso de Lingüística General, Madrid, Universidad Autónoma de Madrid, 2008, págs. 1586-1606.

PING SHIH, Hu, Las frases proverbiales en chino y en español, Tesis doctoral, Madrid, Universidad Complutense de Madrid, 1990. 
QUIROGA, Paula, Fraseología italo-española. Aspectos de lingüística aplicada y contrastiva, Granada, Granada Lingvistica, 2006.

RoDríGueZ REINA, María del Pilar, «Cómo abordan la fraseología los diccionarios bilingües italiano-español del siglo XX desde perspectivas marinas», en Gloria Corpas Pastor (ed.), Las lenguas de Europa. Estudios de fraseología, fraseografía y traducción, Granada, Comares, 2000, págs. 321-345.

Romero GANUZA, Paula, «La delimitación de las unidades fraseológicas (UF) en la investigación alemana y española», Interlingüística, 17, 2007, págs. 905-14.

SAlah Eldin Shalan, Mona, «Paralelismo en la Fraseología Coloquial: estudio contrastivo español-árabe», en Hala Awaad y Mariela Insúa (eds.), Textos sin fronteras. Literatura y sociedad, II, Pamplona, Universidad de Navarra (Ediciones digitales del GRISO), págs. 201-214, 2010.

SAMEER RAYYAN, Mohammad, Fraseología y lingüística informatizada: elaboración de una base de datos electrónica contrastiva árabeespañol/español-árabe de fraseologismos basados en partes del cuerpo, Tesis doctoral, Granada Universidad de Granada, 2014.

SANCHO CREMADES, Pelegrí, «Análisis contrastivo de la fraseología: la expresión del rechazo del discurso previo en catalán y español», III Congreso de Lingüística General, Salamanca,1999, págs. 1475-1482.

SANTAMARÍA PÉREZ, María Isabel, La fraseología española en el diccionario bilingüe español-catalán: aplicaciones y contrastes, Alicante, Ediciones de la Universidad, 2003.

SANTAMARÍA SALINAS, Laura, Análisis contrastivo inglés-español de la fraseología (expresiones idiomáticas y refranes) presente en Asterix in Belgium y Asterix in Spain, Soria, Universidad de Valladolid, 2008.

SARDELli, Maria Antonella, Las paremias de Blasco de Garay en las Cartas de refranes: su correspondencia italiana, Madrid, Universidad Complutense de Madrid, 2007.

SBARBI Y OSUNA, José María, Florilegio o ramillete alfabético de refranes y modismos comparativos y ponderativos de la lengua castellana, Madrid, Ediciones Atlas, 1980.

SCANDOLA CENCI, Viviana, «Crusca frente a Autoridades: análisis contrastivo (con especial atención al tratamiento de la fraseología)», Quaderns de filología. Estudis_lingüístics, 9, 2004, págs. 257-278. 
ScIUTTO, Virginia, «Unidades fraseológicas: un estudio contrastivo de los somatismos del español de Argentina y del italiano», en Actas del XXIII Congreso de AISPI. Linguistica contrastiva tra italiano e lingue iberiche, Palermo, AISPI, 2005, págs. 502-518.

SEVILla MuÑOZ, Julia y ARroyo OrTEGA, Alvaro, «La noción de expresión idiomática en francés y en español», Revista de Filología Francesa, 4, 247261.

SeVIlla Muñoz, Julia y SeVILla MuÑoz, Manuel, «La aplicación de las técnicas de la 'traducción paremiológica' a las paremias populares relativas al vocablo pez en español, inglés y francés», Paremia, 2, 2005, págs. 349-368.

SEVILla MuÑOZ, Julia, «Formas paremiológicas y criterios de clasificación (francés-español)», Critica del testo, XI/1-2, 2008, págs. 235-248.

SEVILla MuÑOZ, Julia, «Las paremias españolas: clasificación, definición y correspondencia francesa», Paremia, 2, 1993, págs. 15-20.

SOLANO RoDRíGUEZ, María Ángeles, «Las unidades fraseológicas del francés y del español: tipología y clasificación», Paremia, 21, 2012, págs. 117-28.

SOSINSKI, Marcin, Fraseología comparada del polaco y del español: su tratamiento en los diccionarios bilingües, Granada, Publicaciones de la Universidad, 2006.

SUAREZ CUADRO, Simón José, Análisis comparativo de las unidades fraseológicas que incluyen algún zoomorfismo en los idiomas ucraniano y español, Tesis doctoral, Granada, Publicaciones de la Universidad, 2006.

TABARES Plasencia, Encarnación y BATISTA RodríGUEZ, José Juan, «Unidades fraseológicas especializadas en los contratos de compraventa de inmuebles españoles y alemanes», en Encarnación Tabares Plasencia (ed.), Fraseología jurídica contrastiva español-alemán/Kontrastive Fachphraseologie der spanischen und deutschen Rechtssprache, Berlin, Frank/Timme, 2014, págs. 97-147.

TABARES Plasencia, Encarnación y PÉREZ VigARAy, Juan Manuel, «Fraseología terminológica: estado de la cuestión y ejemplo de análisis contrastivo», Revista de Filología de la Universidad de La Laguna, 25, 2007, págs. 567577.

TIMOFEEVA, Larissa y RuIz GuRILlO, Leonor, «La ironía en locuciones nominales del español y del ruso», en María Isabel González Rey (ed.), A Multilingual 
Focus on Contrastive Phraseology and Techniques for Translation, Hamburg, Verlag Dr. Kovac, 2008, págs. 247-270.

TRIVIĆ, Aneta, «Correspondencia recíproca en la fraseología. Análisis contrastivo español-serbio», Colindancias, 4, 2013, págs. 69-80.

Vicente Llavata, Santiago, «Análisis contrastivo de fraseología (españolcatalán): en busca de los universales fraseológicos», Res Diachronicae, 2, 2003, págs. 414-421.

WU, Fan, «Análisis comparativo de la manipulación fraseológica en las lenguas china y española», ELUA, 29, 2015, págs. 359-372

WU, Fan, «Estudio fraseológico contrastivo del cerdo en chino y español», Paremia, 19, 2010, págs. 171-178.

ZAMORA MuÑOZ, Pablo, «Análisis contrastivo español-italiano de expresiones idiomáticas y refranes», Paremia, 6, 1996, págs. 87-94.

ZAMORA MuÑoz, Pablo, «Equivalencias lingüísticas de algunas frases idiomáticas pragmáticas italianas en español», Paremia, 8, 1999, págs. 529-35.

ZAMORA MuÑOZ, Pablo, Estudio contrastivo español-italiano de frases hechas, Murcia, Publicaciones de la Universidad, 1995.

Zholobova, Anna, Unidades fraseológicas de origen bíblico en español y ruso, Tesis doctoral, Granada, Ediciones de la Universidad, 2011.

ZURDO RUIZ-AYÚCAR, María Teresa, «Sobre la adecuación del método contrastivo para el análisis interlingüístico de fraseologismos», en B. Eggelte Heinz y V. González Martín (eds.), La lengua alemana y sus literaturas en el contexto europeo. Siglo XIX y XX. Estudios dedicados a Feliciano Pérez Varas, Salamanca, Ediciones de la Universidad, 1999, págs. 353-366.

En la sección siguiente, la tercera, vamos una serie de trabajos que tienen una mezcla entre el estudio traductológico y contractivo de la fraseología española:

AAVV, Proverbios españoles. Traducidos al inglés, al francés, al alemán y al italiano, Madrid, SGEL, 1999.

ABDi YatTou, Hanane, Análisis contrastivo y estudio de una base de datos paremiológica temática hispano-francés-árabe. Problemas de traducción de equivalencia, Tesis doctoral, Alicante, Publicaciones de la Universidad, 2016. 
Amigo Tejedor, Melisa, «Estudio de la fraseología en la novela de Carmen Martín Gaite Entre visillos y de su traducción francesa», Paremia, 19, 2010, págs. 179-186.

ÁNGELOVA NÉNKOVA, Véselka, «Somatismos fraseológicos en búlgaro y español: contraste de unidades fraseológicas desde la praxis traductora», en Joaquín García-Medall (ed.), Fraseología e ironía. Descripción y contraste, Lugo, Editorial Axac, 2006, págs. 97-110.

ASSAM, Boazza, Fraseología y traductología: Aproximación semántico-pragmática al análisis traductológico de las unidades fraseológicas entre el árabe y el español, Tesis Doctoral, Madrid, Universidad Autónoma de Madrid, 2006.

AssAm, Bouazza, «Enfoque discursivo de la traducción de la fraseología: aplicación a la traducción del árabe al español», Revista del CES Felipe II, 9, 2008, págs. 1-9.

BARSANTI VIGO, María Jesús, Estudio paremiológico contrastivo de la traducción de El Quijote de Ludwig Tieck, Salamanca, Ediciones de la Universidad, 2003.

Bogomilova Atanasova, Denitsa, «Traducción de la fraseología en el cuento folklórico. Notas de una traductora de cuentos búlgaros al español», Paremia, 7, 1998, págs. 135-140.

BoughaBA, Mohammed, «Las unidades fraseológicas y la traducción de culturemas entre el español y el árabe», Paremia, 23, 2014, págs. 209-216.

BRUMME, Jenny, «La traducción de la frase hecha. El caso del castellano de Cataluña», en María Isabel González Rey (ed.), A Multilingual Focus on Contrastive Phraseology and Techniques for Translation, Hamburgo, Dr. Kovac, 2008, págs. 55-72.

CORPAS PASTOR, Gloria, «Las colocaciones como problema en traducción actual (español/ inglés)», Revista del departamento filología moderna, 2-3, 1992, págs. 179-186.

CORPAS PASTOR, Gloria, Diez años de investigación en fraseología: Análisis sintáctico-semánticos, contrastivos y traductológicos, Frankfurt am Main/Madrid, Vervuert/Iberoamericana, 2003.

DíAz PERrero, Ana María, «La traducción de las paremias del portugués al español»,

Leandro Félix Fernández y Emilio Ortega Arjonilla (coords), II Estudios 
sobre Traducción e Interpretación, Málaga, Diputación Provincial de Málaga, 1998, págs. 1187-1195.

FERNÁNDEZ ÁlVAREZ, Eva, Refranes y refranes modificados en la prensa alemana: propuestas prácticas de traducción al español a partir de ejemplos de la Süddeutsche Zeitung, Salamanca, Ediciones de la Universidad, 2011.

FLORES ACUÑA, Estefanía, y SANCHO VERA, Cristina, «La fraseología religiosa en español y su traducción al inglés y al italiano: estudio de los diccionarios bilingües Larousse y Herder», en Anne Barr et al. (coords.), Últimas corrientes teóricas en los estudios de traducción y sus aplicaciones, Salamanca, Publicaciones de la Universidad, 2001, págs. 200-212.

GARCÍA ALBERÓ, Javier, El refrán en las versiones clásicas del Quijote al francés y al alemán. Estudio traductológico, paremiológico, lingüístico e históricocultural, Tesis doctoral, Alicante, Ediciones de la Universidad, 2013.

GonzÁlez Royo, Carmen y Mogorrón Huerta, Pedro (eds.), Fraseología contrastiva: lexicografía, traducción y análisis de corpus, Alicante, Publicaciones de la Universidad, 2011.

GuILlÉn MonJE, Gonzalo, «Análisis comparativo del componente verbal en las unidades fraseológicas rusas y españolas y sus aplicaciones a la traducción», en José Antonio Sabio et al. (eds.), Traducción, lengua y cultura (VIII Jornadas Hispano-Rusas de Traducción e Interpretación), Granada, Método, 2004, págs. 163-171.

GUTIÉRREZ RUBIO, Enrique, «Relación entre la motivación conceptual de unidades fraseológicas y las estrategias traductológicas (español-checo)», Studia Romanistica, 15, 2015, págs. 51-59.

LAPEDOTA, Domenico Daniele, Unidades sintagmáticas léxicas en Cinco horas con Mario, de Miguel Delibes, y en sus traducciones al italiano. Hipótesis de discurso fraseológicamente sexuado, Tesis doctoral, Piazza Umberto, Università degli studi di Bari Aldo Moro, 2017.

LEIVA RoJO, Jorge, «La traducción de unidades fraseológicas (alemán español/español alemán) como parámetro para la evaluación y revisión de traducciones», en Carmen Mellado Blanco (coord.), La fraseología del alemán y el español: lexicografía y traducción, München, Peniope, 2013, págs. 31-42. 
LeIVA Rojo, Jorge, La recepción de la obra de Rossana Campo en España y Alemania: la traducción de los componentes oral y fraseológico en mai sentita cosi bene, Tesis doctoral, Málaga, Publicaciones de la Universidad, 2005.

LOZANO, C. W., «La traducción de las expresiones idiomáticas francés-español», en Jorge Fernández-Barrientos Martín (ed.), Actas de las Jornadas Internacionales de Lingüística Aplicada. Roberto Di Pietro. In Memoriam, Granada, Publicaciones de la Universidad, 1993, págs. 653-662.

MACíAs OtÓN, Elena, «La traducción de fraseologismos jurídicos en clase de Terminología (francés-español)», en David García Prieto (Dir.), Enfoques actuales para la traducción fraseológica y paremiológica, Madrid, Instituto Cervantes, 2015, págs. 213-237.

MIRANDA MÁRQUEZ, Gonzalo, Estudio comparativo de las unidades fraseológicas de las lenguas china y española. Problemas lingüísticos y culturales en la traducción de las UFs de una a otra lengua, Tesis doctoral, Granada, Ediciones de la Universidad, 2013.

Mogorrón Huerta, Pedro, y González Royo, Carmen (eds.), Estudios y análisis de fraseología contrastiva: lexicografía y traducción, Alicante, Publicaciones de la Universidad, 2008.

Molina PlAZA, Silvia, «La traducción de las unidades fraseológicas inglés-español: el caso de las colocaciones y las frases idiomáticas», en Luis González y Pollux Hernúñez (coords.), Las palabras del traductor. Actas del II Congreso 'El español, lengua de traducción', Bruselas, Editorial Esletra, 2004, págs. 427443.

Murillo Melero, Miguel, y DíAs Ferrero, Ana María, «La traducción de las expresiones idiomáticas en portugués y español. Análisis comparativo de algunas expresiones idiomáticas relacionadas con el vestuario», en Luis Charlo Brea (ed.), Reflexiones sobre la traducción. Actas del Primer Encuentro Interdisciplinar "Teoría y Práctica de la Traducción", Cádiz, Ediciones de la Universidad, 1994, págs. 227-243.

NAVARRo BRotons, Lucía, Las paremias y sus variantes: análisis sintáctico, semántico y traductológico español-francés, Tesis doctoral, Alicante, Ediciones de la Universidad, 2013.

Peñuela Rodríguez, Susan Carolina y Rojas Velásquez, David Alonso, Análisis de la traducción de las expresiones idiomáticas colombianas del español al 
inglés y al francés en el libro Crónica de una muerte anunciada, Cali, Universidad del Valle, 2008.

PINTORI OlivotTo, Adriana, Modismos, locuciones y expresiones idiomáticas: un estudio contrastivo italiano-castellano, Tesis doctoral, Barcelona, Publicaciones de la Universidad, 1991.

Quiroga MunguíA, Paula, «Discurso literario y traducción: La fraseología italiana/española», en M. Casado Velarde et al. (eds.), Análisis del Discurso: Lengua, cultura y valores. Actas de I Congreso internacional. Universidad de Navarra, Pamplona, noviembre 2002, Madrid, Arco/Libros, 2006, págs. 2025-2036.

Quiroga Munguía, Paula, «Enunciados fraseológicos: La traducción de las fórmulas rutinarias español/italiano», Lenguaje y Textos, 22, 2004, págs. 23-33.

Quiroga Munguía, Paula, «Interferencias en la traducción de las unidades fraseológicas del italiano al español», en el Día europeo de las lenguas, Valladolid, Publicaciones de la Universidad, 2006.

QuiRoga Munguía, Paula, «La traducción de las comparativas fraseológicas del italiano al español», en Pablo Cano López (coord.), VI Congreso Internacional de Lingüística Aplicada, Madrid, Arco/Libros, 2007, págs. 731-742.

RABADÁN ÁlvAREZ, Rosa, Equivalencia y traducción: problemática de la equivalencia translémica inglés-español, León, Publicaciones de la Universidad, 1991.

RAKOTONANAHARY, Tahirisoa Ravakiniaina, Las metáforas en las locuciones verbales en malgache: sus estructuras y sus equivalentes de traducción en francés y en español, Tesis doctoral, Alicante, Ediciones de la Universidad, 2006.

RIOZ, Amaya, Fraseología aplicada a la didáctica y a la traducción del español y del alemán, Madrid, Universidad Complutense de Madrid, 2004.

ROMO HerRero, Lidia, La traducción al francés de las estructuras estables del Lazarillo de Tormes, Tesis doctoral, Madrid, Universidad Complutense de Madrid, 2007.

SÁNCHEZ BENEDITO, Francisco, «Problemas planteados en la traducción al inglés de las locuciones españolas en los diccionarios bilingües español-inglés, inglésespañol y sus posibles causas», en Francisco Garrudo y Javier Comesaña 
(eds.), Estudios de Filología Inglesa en Honor de Antonio Garnica, Sevilla, Publicaciones de la Universidad, 2005, págs. 373-389.

SeVIlla MuÑoz, Julia y SeVILla Muñoz, Manuel, «Técnicas de 'traducción paremiológica’ (francés-español)», Proverbium, 17, 2000, págs. 369-386.

SEVILlA MuÑOZ, Julia, «Algunas referencias sobre las traducciones paremiológicas entre el francés y el español», Livius: Revista de estudios de traducción, 2, 1992, págs. 95-106.

SEVILla MuÑOZ, Julia, «Consideraciones sobre la búsqueda de correspondencias paremiológicas (francés-español)», en Gloria Corpas Pastor (ed.). Las lenguas de Europa. Estudios de Fraseología, Fraseografía y Traducción, Granada, Comares, 2000, págs. 411-430.

SEVILlA MuÑoz, Julia, «La traducción al español de algunas paremias francesas», en Margit Raders y Juan Conesa (eds.), II Encuentros complutenses en torno a la traducción, Madrid, Universidad Complutense de Madrid, 1990, págs. 145-150.

SeVILla MuÑoz, Julia, y GonZÁlez RodríGuEZ, Antonio, «La traducción y la didáctica de las expresiones idiomáticas (francés-español)», Équivalences, 24, 1994, págs. 171-182.

SEVILla MuÑoz, Manuel, «Procedimientos de traducción (inglés-español) de locuciones en contexto», Paremia, 18, 2009, págs. 197-207.

Shaban MOHAMmad SALEM, Tarek. La fraseología en español y en árabe: estudio, comparación, traducción y propuesta de un diccionario, Tesis doctoral, Madrid, Universidad Complutense de Madrid, 2013.

TALEB, Mohamed Lemine, Estudio contrastivo y traductológico del refrán en árabe y español: la traducción de refranes hasaníes al español, Granada, Ediciones de la Universidad, 2016.

TRIVIĆ, Aneta, «Equivalencias traductológicas de ciertas locuciones del español y del serbio contemporáneo», Journal of Linguistic Intercultural Education, 4, 2011, págs. 219-238.

VALERO GARCÉS, Carmen, «Las fórmulas rutinarias en la comunicación intercultural: La expresión de emociones en inglés y español y su traducción», en Isabel de la Cruz Cabanillas (coord.), La lingüística aplicada a finales de siglo XX: ensayos y propuestas, Madrid, AESLA, 2001, págs. 635-640.

WotJAK, Gerd, «En torno a la traducción de unidades fraseológicas (con ejemplos tomados del español y el alemán)», Linguistische Arbeitsberichte, 40, 1983, págs. 56-80. 


\section{Consideraciones finales}

Valga decir que la fraseología ya ocupa un lugar destacado entre las disciplinas lingüísticas y forma una rama lingüística independiente. Este trabajo viene dentro de una serie de artículos sobre la fraseología que hemos llevado a cabo desde algunos años que tratan la fraseología en ámbitos variados.

Nuestro artículo esbozó su fin desde el principio: el de diseñar y orientar a los estudiosos a los temas investigados hasta el momento en el campo fraseológico en cuanto a su traducción y a su estudio contrastivo. Este hecho consiste en sí una guía de las cuestiones que todavía hay que ponerse como temas de investigación.

La característica de este tipo de artículos es abrirle al investigador algunas vías de trabajo, ya que sabrá que algunos tipos de investigaciones aún siguen sin búsqueda. La importancia de este trabajo se señala en que hay investigadores que abordaron ciertos puntos que pueden ser considerados por otros como ideas futuras. Por eso, nuestro trabajo deja la puerta abierta para los nuevos investigadores a abordar temas todavía no tratados en la disciplina fraseológica.

Es necesario continuar y llevar a cabo estudios traductológicos de fraseología entre el español y otras lenguas, sobre todo la lengua árabe, como por ejemplo estudios que tengan en cuenta las funciones pragmáticas de las unidades fraseológicas. Está muy claro que aún falta mucho por hacer en el campo de los estudios contrastivos de la fraseología española.

Con este artículo hemos pretendido extender un puente entre los estudiosos para lo que se refiere a los distintos enfoques que hay que abordar dentro del estudio de las unidades fraseológicas. Es interesante pormenorizar que los trabajos acumulados en nuestro repertorio aglutinan una gran diversidad de perfectivas en el estudio traductológico y contrastivo para el tratamiento de la fraseología. Pensamos que en el futuro muy próximo tendríamos que realizar otro repertorio que trata el aspecto didáctico de la fraseología en el proceso de la enseñanza del español como lengua extranjera ${ }^{16}$.

Hemos podido elaborar un listado ciertamente extenso. Es un listado que ayuda a los investigadores para localizar los trabajos existentes al respecto en las diferentes publicaciones sobre el tema.

\footnotetext{
${ }^{16}$ En prensa.
} 